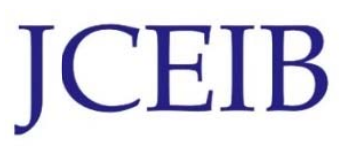

Journal Chemical Engineering and Industrial Biotechnology (JCEIB)

Open Access

Volume 5 pp. 79-90; March 2019

CUniversiti Malaysia Pahang Publisher

DOI: https://doi.org/10.15282/JCEIB.V5.08.29/3/2019/5.5

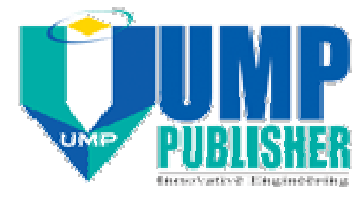

\title{
AN EXPERIMENTAL STUDY OF SHATKORA (CITRUS MACROPTERA) IN A TRAY DRYER : EFFECT ON DRYING KINETICS AND PRODUCT QUALITY
}

\author{
M. Rakib Uddin ${ }^{\mathrm{a},}$, Syeada Nelima Akter ${ }^{\mathrm{b},}$, Md. Shahria Pervez ${ }^{\mathrm{b}}$, \\ Thurga Devi Munusamy ${ }^{\mathrm{c}}$, Md. Maksudur Rahman Khan ${ }^{\mathrm{c} *}$ \\ ${ }^{a}$ Department of Chemical Engineering and Polymer Science; Shahjalal University of Science and \\ Technology; Sylhet-3114, Bangladesh \\ ${ }^{\mathrm{b}}$ Department of Food Engineering and Tea Technology, Shahjalal University of Scienceand Technology, \\ Sylhet 3114, Bangladesh \\ ${ }^{\mathrm{c}}$ Faculty of Chemical and Natural Resources Engineering, Universiti Malaysia Pahang, Lebuhraya Tun \\ Razak, 26300 Gambang, Kuantan, Pahang, Malaysia \\ *E-mail: mrkhancep@yahoo.com \\ Tel: 0088-0821-719400 Fax: 0088-0821-715257
}

\begin{abstract}
Citrus macroptera is a citrus fruit locally known as Shatkora and the fruit of this plant were used for various purposes especially for cooking and also as an odorant in perfume industries.In this research work, Shatkora peel was dried using a laboratory scale tray dryer. The experimental work was conducted at an inlet temperature of $40-60^{\circ} \mathrm{C}$ and velocities from $0.5-0.9 \mathrm{~m} / \mathrm{s}$. Besides, the thickness of the layer was varied between $2-$ $10 \mathrm{~mm}$. The results demonstrated that the rate of drying was increased accordingly with rise in both air temperature and air velocity however a decreased in layer thickness was noticed. At high air temperature, moisture content of solid achieved equilibrium state within short period of time. On the other hand, moisture diffusivity of Shatkora was evaluated by applying Fick's second law and the value was varied from $1.78 \times 10^{-8}$ to $2.83 \times 10^{-7}$. In addition, activation energy was determined by using Arrhenius type relation and $19.70 \mathrm{~kJ} / \mathrm{mol}$ was obtained.
\end{abstract}

Keywords: Drying; Shatkora; Drying rate; Moisture content; Diffusion coefficient.

\subsection{INTRODUCTION}

Citrus macroptera also generally known as Sat kara or Shatkora is the most famous and costly citrus fruits cultivated all over Sylhet areas of Bangladesh. The semi wild species are majorly used for medicinal purpose by local tribes of Assam, India (Nongalleima et al., 2017). In Bangladesh, both green and mature fruits are added as main ingredients for cooking and also to make pickles. Moreover, the sweet flavor of fruits created by essential oil of flavedo parts can be applied for flavoring purposes in perfume 
industries. Annually, Bangladesh earns huge profits by exporting these fruits particularly to UK, USA and Middle East countries. On the other hand, due to high moisture content (approximately $75 \% \mathrm{w} / \mathrm{w}$ ) of the fruits at harvest, it is difficult to be preserved under atmospheric conditions $\left(20-25^{\circ} \mathrm{C}\right)$ for more than couple of days. In spite of the fact that Shatkora can be preserved in refrigerator but in Bangladesh very smaller number of population has access to have refrigerator. Therefore, the easiest and cheapest preservation technique to keep this fruits for a longer period of time is through drying.

Drying is depicted as one of the best methods to remove moisture in which transferring both mass and heat simultaneously. This method also known to be a conventional technique for preserving foods, which guaranteed longer shelf-life, lighter load for transportation as well as only small space are required for storage (Ertekin \& Yaldiz, 2004). In contradiction with fresh vegetables which could sustain for only couple of days under atmospheric conditions, dry items are possible to be kept for a considerable length of time or even years without losing any appreciable nutrients. Bulk weight also can be reduced by drying methods, thus facilitating ease of transportation. At times, drying may prompt an extensive decrease in volume and consequently reduced the space required for storage.

Various factors for instance batch size, properties of the materials used, moisture contents of the products, climate changes, and the demand for the dried products should be considered for any procedures employed for drying. Apart from that, most of the review on literature regarding comprehensive study of drying agricultural materials often relates by either investigating the products behavior during drying or exploring different drying technologies. Consequently, various researches on thin layer drying of fruits (Doymaz, 2004a, 2004b; Simal et al., 2005), vegetables (Doymaz, 2004c), grains(Cao et al., 2004), leaves and grasses (Demir et al., 2004; Mujaffar \& John, 2018) have been reported. In spite of that, locally Shatkora is preserved by the sun drying, which is time consuming and product quality may be low. Nevertheless, it can be claimed that no literature has been studied on the thin layer drying of Shatkora in a convectional dryer. Therefore, in this experiment Shatkora was dried in a tray dryer and this paper further described the characteristics of Shatkora resulted from drying. The current work targeted to further explore the effect of temperature, air velocity and layer thickness of Shatkora peels as well as the variation with time. Moreover, the underlying quality of Shatkora by drying will be checked by measuring vitamin $\mathrm{C}$ content.

\subsection{Equipment}

\subsection{MATERIALS AND METHODS}

A thin layered dryer (model UOP 8, ARMFIELD LIMITED, ENGLAND) was used to conduct the experiment and the schematic diagram are shown in Figure 1. 


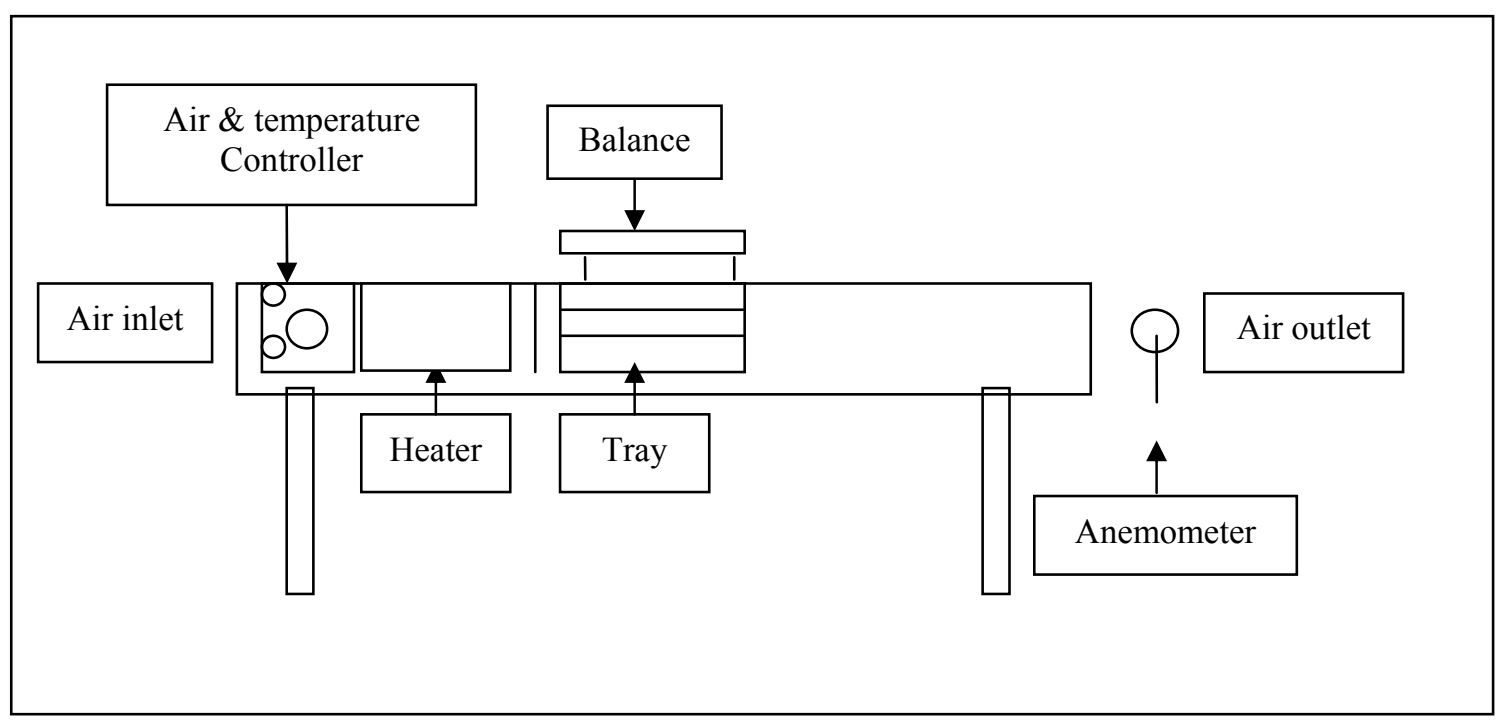

Figure 1: Schematic diagram of tray dryer

Firstly, air is drawn into the duct and passes through a mesh guard and the speed is controlled by axial flow fan impeller to generate velocities up to $1.5 \mathrm{~m} / \mathrm{s}$. Additionally, in order to control the air flow over an electrically heated element, a power regulator is used to vary the temperature up to $80^{\circ} \mathrm{C}$. After that, the air flows into the center of the duct where samples to be dried are placed on the trays. Subsequently, a support frame is used to carry the trays where it is connected to a digital balanceand the weight of sample is detected consistently.

A side door that is locked with a glass panel is used as a pathway to keep or remove the trays and also to monitor the conditions of the samples. After across the trays, an outlet duct section is used to discharge the air to the atmosphere, where a vane anemometer, evaluating air velocity is located. An aspirated psychrometer in which the power is supplied by a socket outlet attached on the control panel is used to determine both the wet and dry temperatures. The psychrometer are pertains to both up and down streams of the drying trays and are covered by flaps when not in use.

The equipment has an overall dimension of $(1.40 \times 2.95 \times 0.73 \mathrm{~m})$. The heating unit is constructed with an inner chamber $(25 \times 25 \times 25 \mathrm{~cm})$ using a steel sheet and enclosed with an outer chamber $(35 \times 35 \times 35 \mathrm{~cm})$ by a soft board. The fiberglass insulating materials was employed to fill the gap between the two chambers. Finally, the air passes through plenum chamber $(37 \times 37 \times 25 \mathrm{~cm})$ after leaving the heating chamber for mixing and to obtain constant temperature and enter the drying chamber. 


\subsection{Evaluation of vitamin $C$ content}

The amount of Vitamin $\mathrm{C}$ presentin Shatkora for both prior to and after drying was calculated using a standard method provided by (Majidi et al., 2016).

\subsubsection{Preparation of samples}

Ten grams of Shatkora peels was blended with a laboratory blender (CHRISTISON) and was homogenized with $85 \mathrm{~mL}$ of $10 \mathrm{mM} \mathrm{KH}_{2} \mathrm{PO}_{4}$ (E Merck India Limited) solution $(\mathrm{pH}=1.4)$. A mechanical shaker was used to agitate the solution for about $15 \mathrm{~min}$. Next, the solution was poured into a $100 \mathrm{~mL}$ volumetric flask and again stirred gradually until a homogenous dispersionobtained. Thereafter, dilution of the sample was carried out up to the mark with $10 \mathrm{mM} \mathrm{KH}_{2} \mathrm{PO}_{4}$ solution. Subsequently, the solution was filtered and the clear supernatant was taken to determine vitamin $\mathrm{C}$ content in the Shatkora.

\subsubsection{Preparation of standards}

About 3 to 4 drops of bromine water were added to $4 \mathrm{~mL}$ of ascorbic acid (Sigma chemical co., Germany) at various concentrations $(10-50 \mathrm{ppm})$ to validate the completion of ascorbic acid oxidation to dehydroascorbic acid. Next, the presence of excess bromine was eliminated by adding 1 to 2 drops of thiourea solution (10\%) until the solution turns clear. In all the standards, $1 \mathrm{~mL}$ of 2, 4-DNPH was mixed thoroughly.

Finally, in order to complete the reactions, both the standards and the samples were kept in water bath (thermostat) at $37^{\circ} \mathrm{C}$ for $3 \mathrm{~h}$. Once incubation was done, ice bath was used to cool the solutions and the solutions were mixed with $5 \mathrm{~mL}$ of $85 \% \mathrm{H}_{2} \mathrm{SO}_{4}$ under constant stirring until a colored solution was obtained. For obtaining a calibration curve the absorbance of the standards were plotted against their corresponding concentrations.

\subsubsection{Estimation of vitamin C by UV method}

Ascorbic acid of different concentrationswere taken as a source of vitamin $\mathrm{C}$ and the absorbance was evaluated at $520 \mathrm{~nm}$ by UV-visible spectrophotometer (SHIMASZU, UV-1601). Figure 2 shows the calibration curve in which was prepared by plotting absorbance versus concentration of ascorbic acid. Additionally, this curve was being as a reference to measure the vitamin $\mathrm{C}$ content of the sample for both before and after drying. 


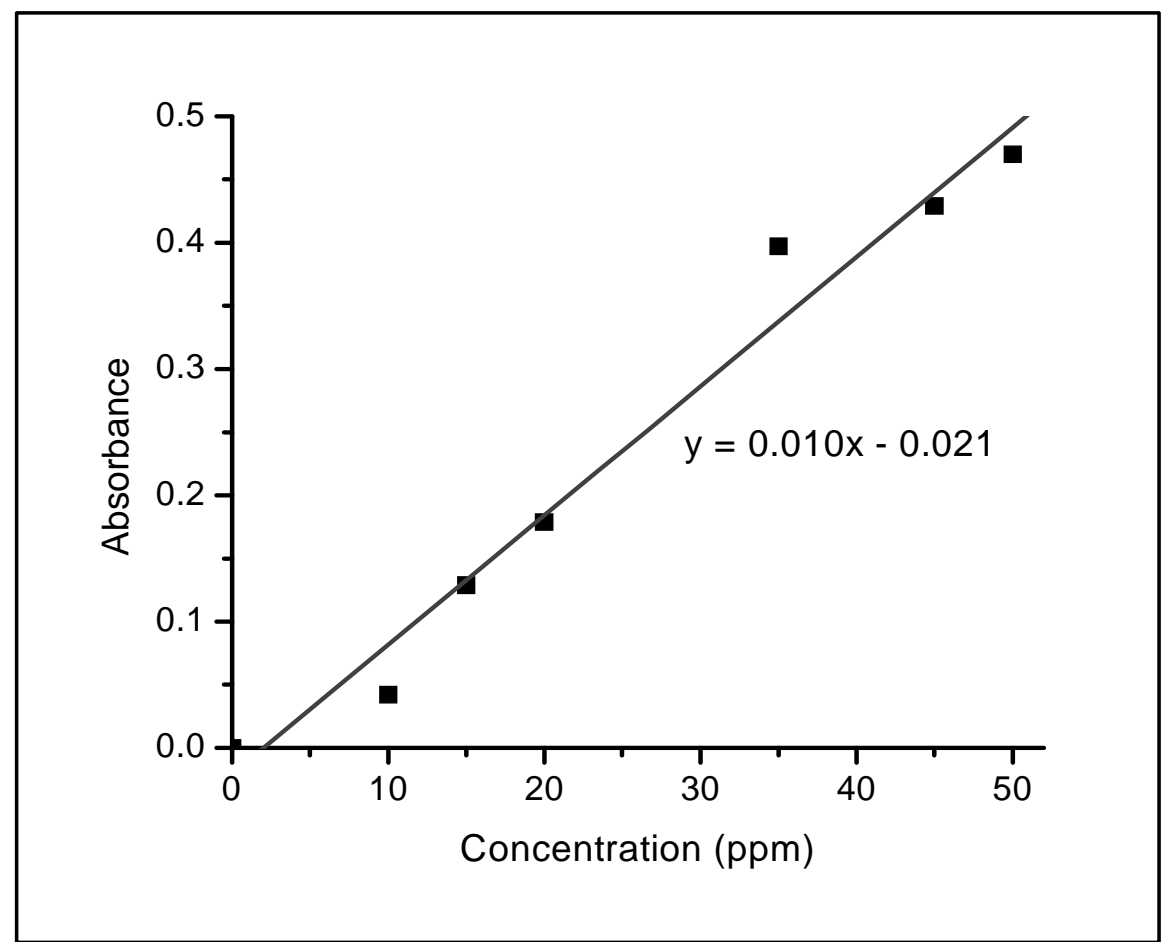

Figure 2: Calibration curve for Vitamin C content

\subsection{Dying experiments}

Fresh Shatkora was collected from local area and stored at $4{ }^{\circ} \mathrm{C}$ before the experiments. Hereby, only the peels of Shatkora were utilized in this research. The Shatkora were prepared by cutting them into smaller pieces and the fruits were removed from the peel. Prior to drying, the empty dryer was initially set to a fixed temperature and wait for at least $30 \mathrm{~min}$ to attain steady state before placing the Shatkora peels into the dryer. The sample mass was examined using a digital balance and afterwards placing into the dryer. Subsequently, the mass of the sample was recorded for every 10 min of time intervals. In the course of drying, Shatkora were exposed for drying until the moisture content reaches recommended method for forage materials. One-factor-at-a-time (OFAT) approach was employed to screen the reaction conditions and the experimental ranges were chosen based on the previous studies (Nicoleti et al., 2001; Rajkumar et al., 2007; Kaya \& Aydın, 2009; Ben et al., 2014). Various temperatures at the range of (40$60^{\circ} \mathrm{C}$ ) were tested and the best temperature was selected as a constant for the second parameter. Next, the Shatkora peels were widely spread on a tray to an estimated depth ranging from $(2-10 \mathrm{~mm})$. Finally, the air velocity was varied from $(0.50-0.90 \mathrm{~m} / \mathrm{s})$ at an optimum temperature and thickness.

\subsection{Theory}

The moisture content of Shatkora with respective to time was determined from the dry weight basis and was calculated by using equation (1);

$$
X=\frac{W-W_{S}}{W_{S}}(1)
$$


where, $\mathrm{W}$ and $\mathrm{W}_{\mathrm{s}}$ is the weight of the sample at time $\mathrm{t}$ and mass of the bone dry solid respectively.

Generally, a simplified method was used to predict the diffusion coefficient (Zogzas et al., 1994). For a thin plate, Baroni and Hubinger (1998) provided equation for Fick's law of diffusion, with assumptions that the transferring of moisture is only occur by diffusion, negligible shrinking, constant diffusion coefficients and temperature as well asprolonged time of drying, are given in equation (2);

$\frac{X-X_{e}}{X_{o}-X_{e}}=\sum_{n=0}^{n=1} \frac{8}{(2 n+1) 2 \pi^{2}} \exp \left(\frac{-D_{e f f}(2 n+1)^{2} \pi^{2} t}{4 \ell^{2}}\right)$

where, $\ell$ is the total slab thickness if drying only from top region, $D_{\text {eff }}$ is the effective diffusivity and $\frac{X-X_{e}}{X_{o}-X_{e}}$ is the dimensionless moisture ratio.

As compared to $\mathrm{X}$ or $\mathrm{X}_{\mathrm{o}}$, the value of equilibrium moisture content is relatively small (low air relative humidity). Thus $\frac{X-X_{e}}{X_{o}-X_{e}}$ can be simplified to $X^{\prime \prime}=\frac{X}{X_{o}}$ and equation (2) is modified to equation (3);

$$
X^{\prime \prime}=a \exp ^{-k t}
$$

where, $k=\frac{-D_{e f f} \pi^{2}}{4 \ell^{2}}$, and $a=\frac{8}{\pi^{2}}$

$$
\ln X^{\prime \prime}=-k t+0.21
$$

where, $k=\left(\frac{D_{e f f} \pi^{2}}{4 \ell^{2}}\right)$ is represented by the slope of plot $\ln X^{\prime \prime}$ vs. $\mathrm{t}$

Equation (5) demonstrated the Arrhenius equation which can be used to evaluate the activation energy of the material.

$$
\ln D_{e f f}=\mathrm{C}-\frac{\Delta E}{R T_{a b s}}(5)
$$

where, $\mathrm{R}$ is the rate constant $(\mathrm{R}=8.314 \mathrm{~J} / \mathrm{mol})$.

\subsection{Effect of Shatkora on drying kinetics}

Moisture content at different time with respect to various parameters including air temperature, air velocity and thickness of the materials are shown in Figure 3, Figure 4 and Figure 5 respectively. The trend of the graph displays that decline of moisture content with time was in the form of non-linear style, demonstrating that the migration of moisture is restrained by diffusion and further subjected to the moisture in the 
Shatkora peels. Moreover, the drying rate was increased with increasing temperature. The difference in moisture content with time for Shatkora layer within the temperature range of $40-60^{\circ} \mathrm{C}$ and thickness of $6 \mathrm{~mm}$ are shown Figure 3 . It was noticed that the time for dried out the samples were decreased drastically by increasing the drying air temperature and this outcome supported the characteristics of most high moisture vegetables. At air temperature $40^{\circ} \mathrm{C}$, the moisture contents can only be reduced up to 2.0 (decimal dry basis) or lesser however at $60^{\circ} \mathrm{C}$, the reduction in moisture content was doubled and similar result was reported by (Gikuru \& Joseph, 2005).

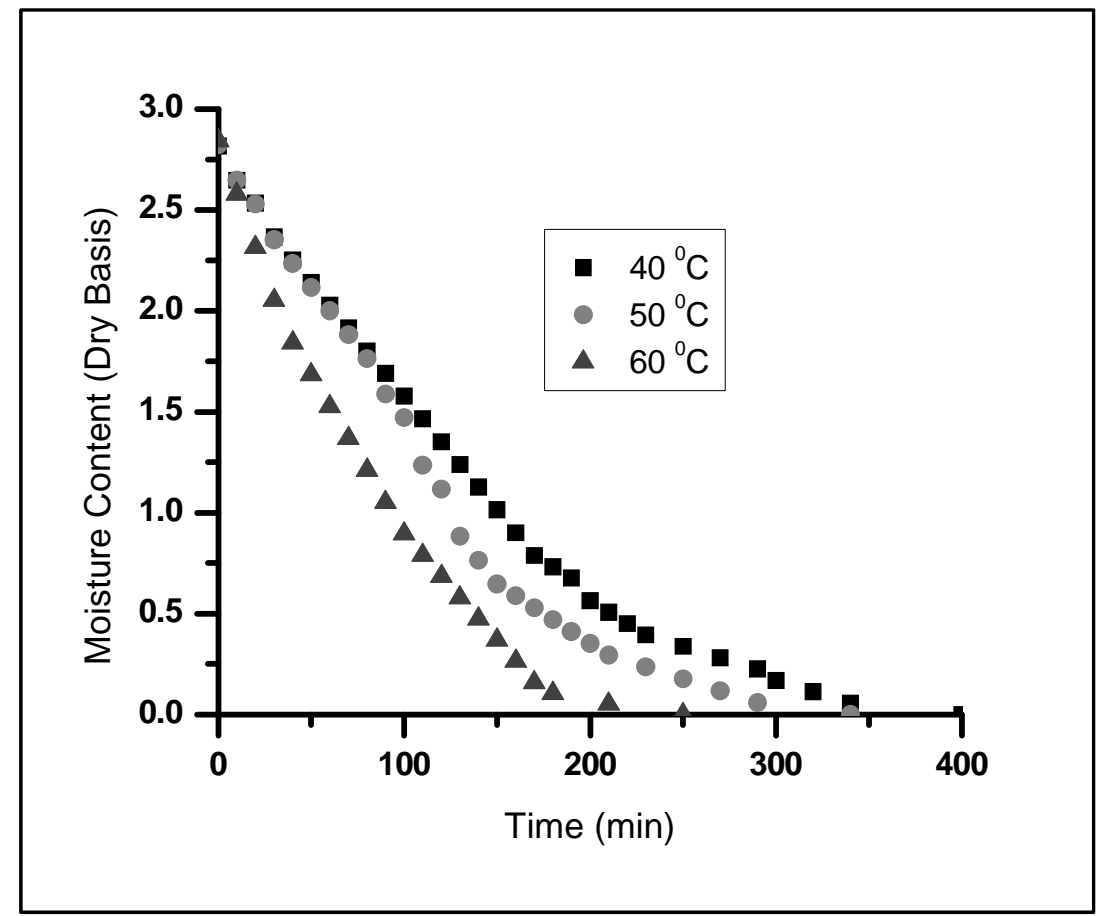

Figure 3: Variation of moisture content respect to drying air temperature

The rate of drying was also influenced by air velocity. The variation in moisture content versus time when drying Shatkora layer with a thickness of $2 \mathrm{~mm}$ and within the velocity ranges 0.5 to $0.9 \mathrm{~m} / \mathrm{s}$ at constant temperature is shown in Figure 4 . 


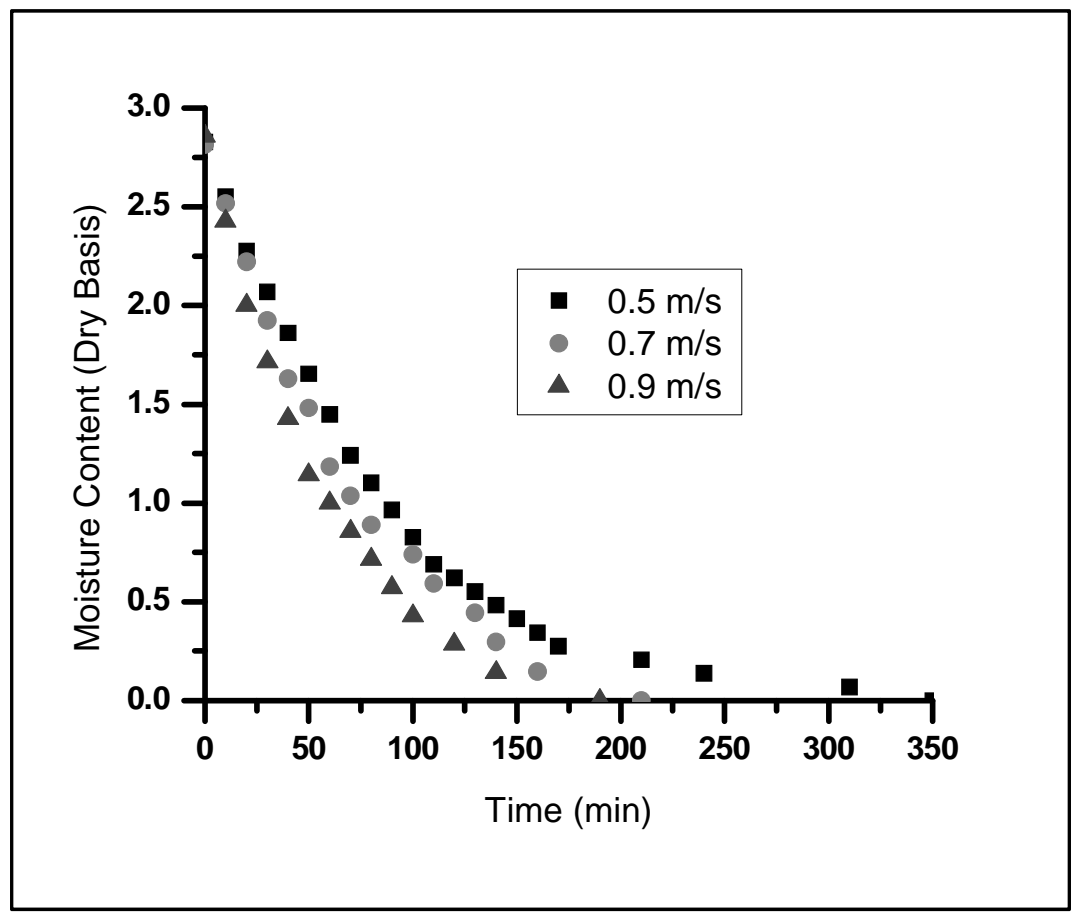

Figure 4: Variation of moisture content with time and drying air velocity

From Figure 4, it was observed that increase in air velocity causes the drying time to be rapidly decreased while increasing the removal of free moisture. At air velocity of 0.5 $\mathrm{m} / \mathrm{s}$, the time required to remove the moisture content was doubled as compared to the drying time required at air velocity of $0.9 \mathrm{~m} / \mathrm{s}$. Thus, it can be concluded that when the air flow velocity increase, the time required to reach certain moisture content was shortened and this result supported the outcome found by (Hayaloglu et al., 2007).

Besides, when the thickness of the Shatkora layer was magnified, a comparative trend in the relationship between time of drying and temperature was noticed and are presented in Figure 5. At thickness $10 \mathrm{~mm}$, the drying time required to remove the moisture content was approximately twice as compared to thickness of $2 \mathrm{~mm}$ and a similar trend was reported by (Mwithiga \& Olwal, 2005). Therefore, this is an evident that increasing thickness increases the drying time whereas decreases the removal of free moisture. 


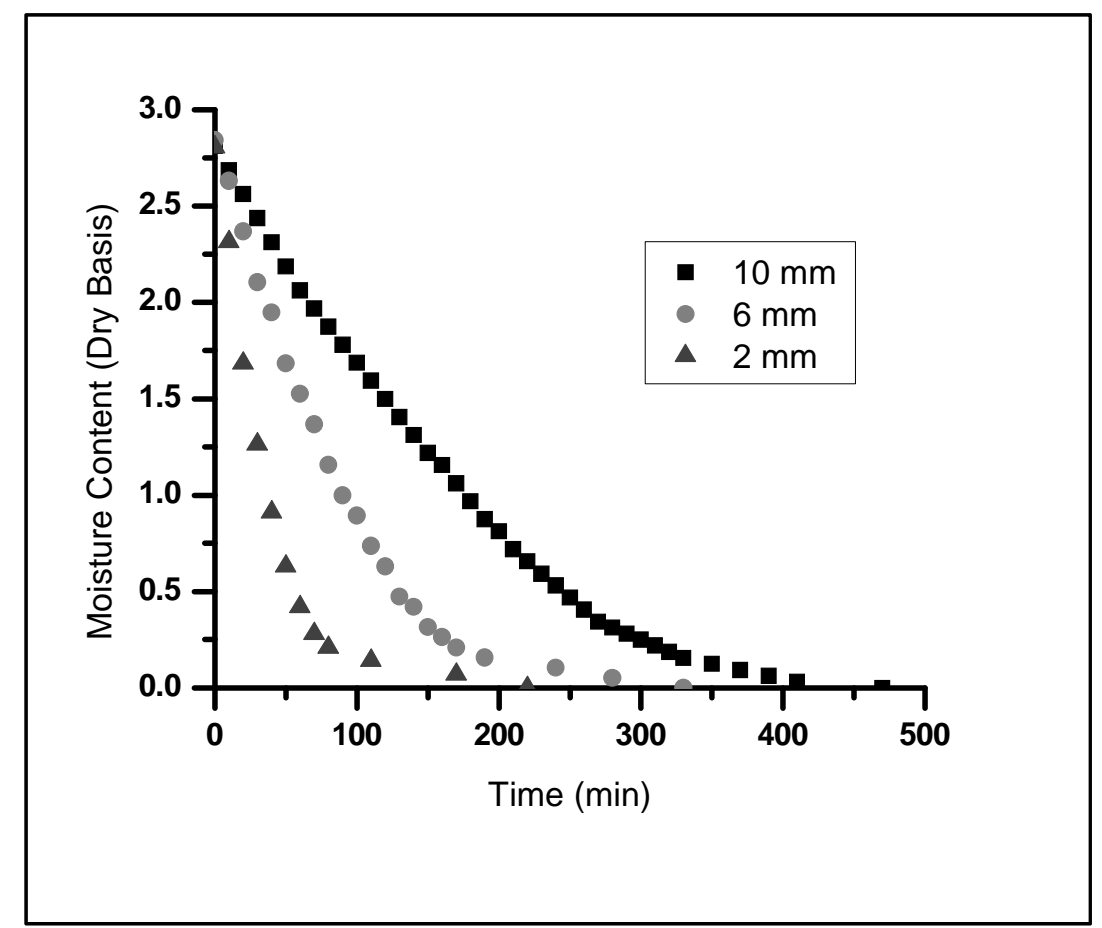

Figure 5: Variation of moisture content respect to drying thickness

The effective diffusivity, $\mathrm{D}_{\text {eff }}$ and rate constant, $\mathrm{k}$ was determined by plotting In X" vs $\mathrm{t}$ for various temperature, velocity and thickness and are shown in Figure 6. On the other hand, the diffusivity constant was referred to an Arrhenius type relationship and is depicted in Figure 7. The activation energy of Shatkora was also determined by using Figure 7 and equation (4) and found to be $19.70 \mathrm{~kJ} / \mathrm{mol}$, within the range of 12.87$58.15 \mathrm{~kJ} / \mathrm{mol}$ (Senadeera et al., 2003).

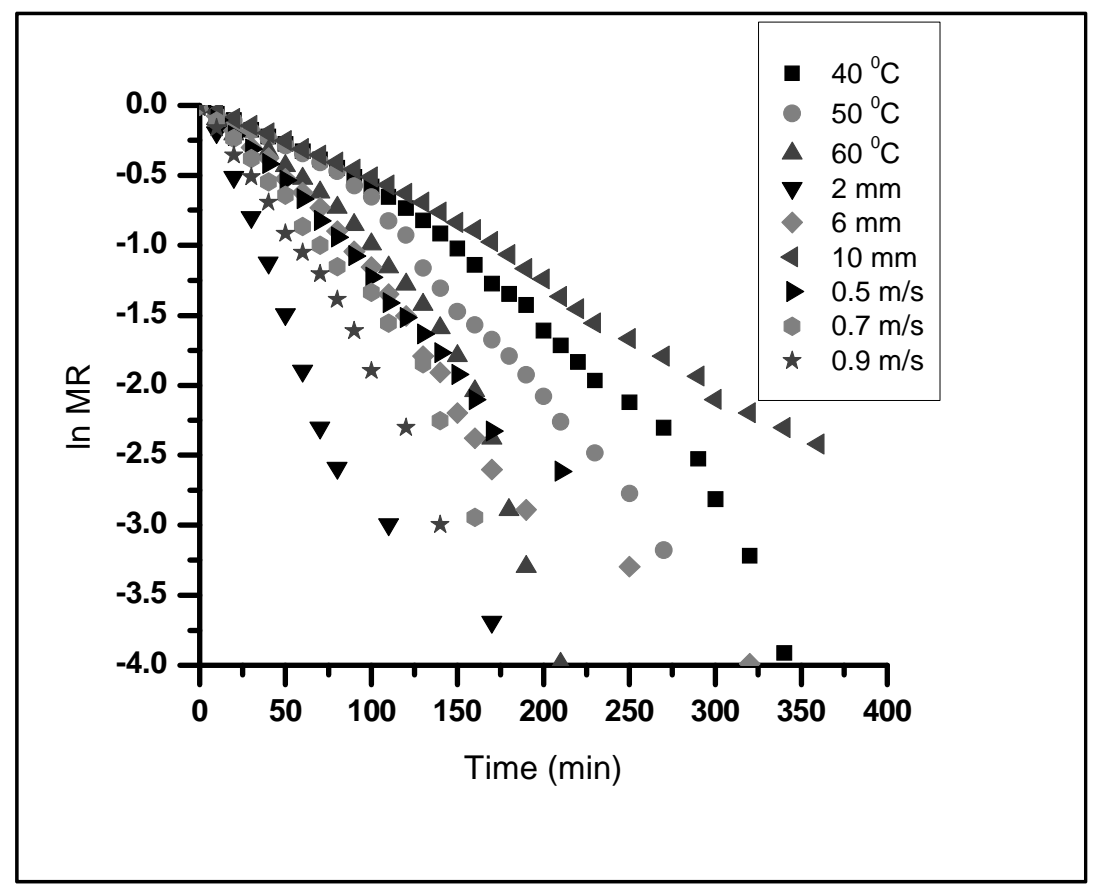

Figure 6: Logarithm of moisture ratio versus time for determining k value 


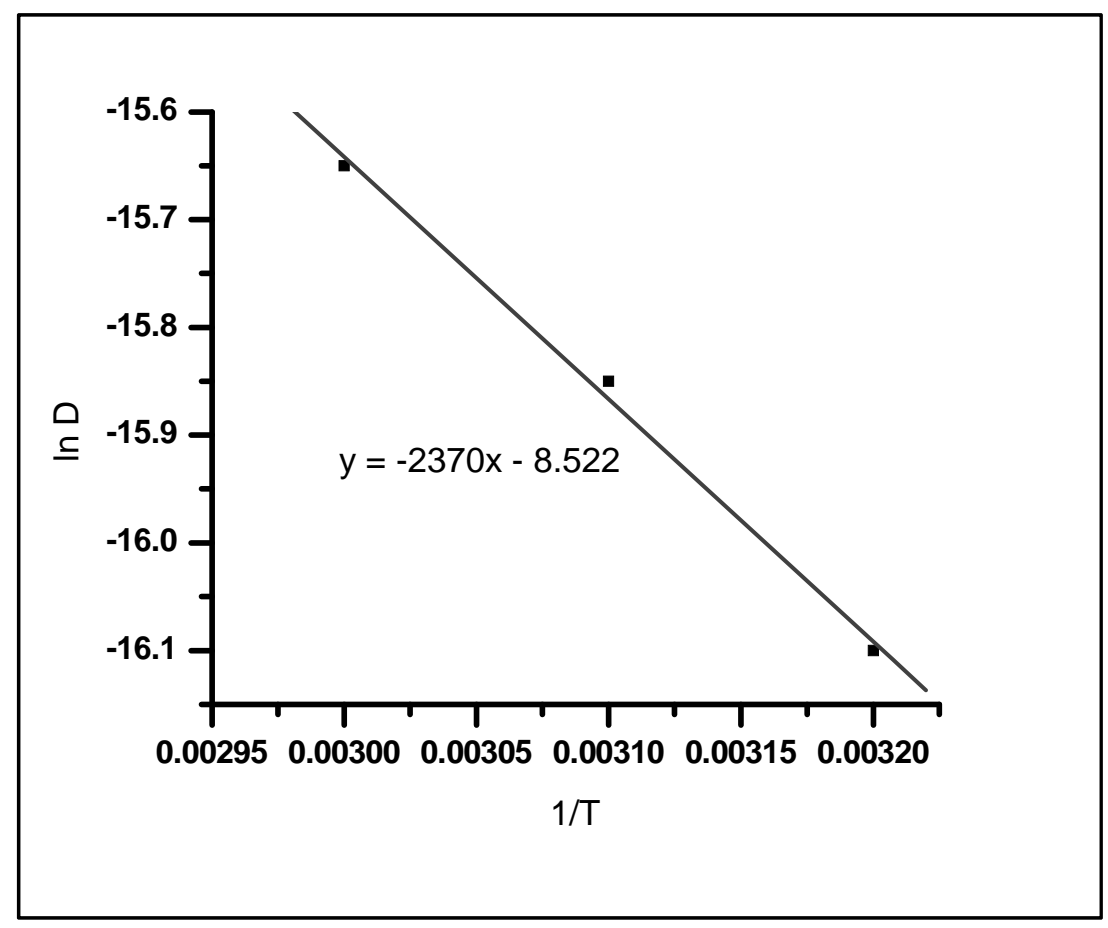

Figure 7: Logarithm of thermal diffusivity versus inverse of absolute temperature

The values of rate constant $(k)$, effective diffusivity $\left(D_{\text {eff }}\right)$ and activation energy $(\Delta E)$ are summarized in Table 1.

Table 1: Drying rate constant, effective diffusivity and activation energy for Shatkora at different drying conditions

\begin{tabular}{llllc}
\hline Parameters & Conditions & $\mathrm{k}\left(\mathrm{min}^{-1}\right)$ & $\mathrm{D}_{\text {eff }}\left(\mathrm{m}^{2} / \mathrm{s}\right)$ & $\begin{array}{l}\text { Activation energy, } \\
\Delta \mathrm{E}(\mathrm{kJ} / \mathrm{mol})\end{array}$ \\
\hline Temperature $\left({ }^{\circ} \mathrm{C}\right)$ & 40 & 0.005 & $1.02 \times 10^{-7}$ & \\
& 50 & 0.006 & $1.31 \times 10^{-7}$ & \\
& 60 & 0.008 & $1.60 \times 10^{-7}$ & \\
& 0.5 & 0.005 & $1.78 \times 10^{-8}$ & \\
Velocity $(\mathrm{m} / \mathrm{s})$ & 0.7 & 0.011 & $2.10 \times 10^{-8}$ & 19.70 \\
& 0.9 & 0.029 & $2.75 \times 10^{-8}$ & \\
Thickness & 2 & 0.012 & $4.38 \times 10^{-8}$ & \\
$(\mathrm{~mm})$ & 6 & 0.014 & $1.89 \times 10^{-7}$ & \\
& 10 & 0.017 & $2.83 \times 10^{-7}$ & \\
\hline
\end{tabular}

\subsection{Quality changes by drying Shatkora peels}

The quality (ascorbic acid) loss of Shatkora before and after drying at $60^{\circ} \mathrm{C}$ was also observed. It was found that after drying the Shatkora at $60^{\circ} \mathrm{C}$, loss of the amount of ascorbic acid was not significant. Therefore, it can be concluded that, Shatkora can be preserved by drying at $60^{\circ} \mathrm{C}$. Table 2 shows the amount of Vitamin $\mathrm{C}$ presents in both fresh and dried Shatkora fruits. 
Table 2: Vitamin C content in fresh and dried Shatkora

\begin{tabular}{lllllll}
\hline Sample & $\begin{array}{l}\text { No. of } \\
\text { observation }\end{array}$ & Absorbance & $\begin{array}{l}\text { Concentration } \\
(\mathrm{ppm})\end{array}$ & $\begin{array}{l}\text { Mean } \\
\text { concentration } \\
(\mathrm{ppm})\end{array}$ & $\begin{array}{l}\text { Standard } \\
\text { deviation }\end{array}$ & $\begin{array}{l}\text { Total } \\
\text { Vitamin C } \\
(\mathrm{mg} / 100 \mathrm{~g})\end{array}$ \\
\hline $\begin{array}{l}\text { Fresh } \\
\text { Shatkora }\end{array}$ & 1 & 0.767 & 76.7 & & & \\
$\begin{array}{l}\text { dry } \\
\text { basis })\end{array}$ & 2 & 0.763 & 76.3 & 76.26 & 0.368 & $76.26 \pm$ \\
$\begin{array}{l}\text { Dried } \\
\begin{array}{l}\text { Shatkora } \\
\text { (dry }\end{array}\end{array}$ & 1 & 0.758 & 75.8 & & & 0.368 \\
basis) & 0.7193 & 71.93 & & & \\
\hline
\end{tabular}

\subsection{CONCLUSIONS}

In this work, sliced Shatkora peels was successfully dried in a tray dryer with a thickness ranging from $(2-10 \mathrm{~mm})$, air temperatures $\left(40-60^{\circ} \mathrm{C}\right)$ and air velocities $(0.5-$ $0.9 \mathrm{~m} / \mathrm{s}$ ). The drying rate was decreased by increasing thickness of the sample. At a given air velocity and thickness, the temperature has a remarkable impact on the drying kinetics of Shatkora. Moreover, when the drying temperature was increased from $40^{\circ} \mathrm{C}$ to $60^{\circ} \mathrm{C}$, reduction in drying time was observed. The result also revealed that at constant temperature, the drying rate was increased with an increase of air velocity. Moreover, the drying rate constant and moisture diffusivity of sample were also increased at both high temperature and air velocity. In this study, effective diffusivity of Shatkora was determined by using Fick's second law and the moisture diffusivity was varied from $1.78 \times 10^{-8}$ to $2.83 \times 10^{-7}$. Activation energy of Shatkora was also determined by the Arrhenius type relation and $19.70 \mathrm{~kJ} / \mathrm{mol}$ was obtained. In contrary, research in the future should take into considerations towards the ways to enhance heated tray dyer based on loading density, fuel and electrical energy requirements.

\section{ACKNOWLEDGEMENT}

The authors are thankful to Shahjalal University of Science and Technology, Bangladesh and Universiti Malaysia Pahang for providing research grant (RDU180355).

\section{REFERENCES}

Baroni, A. F. and Hubinger, M. D. (1998) 'Drying of onion: effects of pretreatment on moisture transport', Drying Technology, 16(9-10), pp. 2083-2094.

Cao, W. et al. (2004) 'Drying Enhancement of Rough Rice by an Electric Field', Biosystems Engineering, 87(4), pp. 445-451. 
Demir, V. et al. (2004) 'Mathematical Modelling and the Determination of Some Quality Parameters of Air-dried Bay Leaves', Biosystems Engineering, 88(3), pp. 325-335.

Doymaz, I. (2004a) 'Convective air drying characteristics of thin layer carrots', Journal of Food Engineering, 61(3), pp. 359-364.

Doymaz, I. (2004b) 'Drying kinetics of white mulberry', Journal of Food Engineering, 61(3), pp. 341-346.

Doymaz, I. (2004c) 'Pretreatment effect on sun drying of mulberry fruits (Morus alba L.)', Journal of Food Engineering, 65(2), pp. 205-209.

Ertekin, C. and Yaldiz, O. (2004) 'Drying of eggplant and selection of a suitable thin layer drying model', Journal of Food Engineering, 63(3), pp. 349-359.

Gikuru, M. and Joseph, O. (2005) 'The drying kinetics of kale (Brassica oleracea) in a convective hot air dryer', Journal of Food Engineering, 71(4), pp. 373-378.

Ben Haj Said, L. et al. (2014) 'Thin layer convective air drying of wild edible plant (Allium roseum) leaves: experimental kinetics, modeling and quality’, Journal of Food Science and Technology.

Hayaloglu, A.A., Karabulut, I., Alpaslan, M. \& Kelbaliyev, G. (2007) 'Mathematical modeling of drying characteristics of strained yoghurt in a convective type tray-dryer', Journal of Food Engineering, 78(1), pp. 109-117.

Kaya, A. and Aydin, O. (2009) 'An experimental study on drying kinetics of some herbal leaves', Energy Conversion and Management, 50(1), pp. 118-124.

Majidi, M. I. H. A. \& Y-ALQubury, H. (2016) 'Determination of Vitamin C (ascorbic acid) Contents in various fruit and vegetable by UV-spectrophotometry and titration methods', Journal of Chemical and Pharmaceutical Sciences, 9(4), pp. 2972 - 2974.

Mujaffar, S. and John, S. (2018) 'Thin-layer drying behavior of West Indian lemongrass ( Cymbopogan citratus ) leaves', Food Science \& Nutrition, 6(4), pp. 1085-1099.

Mwithiga, G. and Olwal, J. O. (2005) 'The drying kinetics of kale (Brassica oleracea) in a convective hot air dryer', Journal of Food Engineering, 71(4), pp. 373-378.

Nicoleti, J. F., Telis-Romero, J. and Telis, V. R. N. (2001) 'Air-drying of fresh and osmotically pre-treated pineapple slices: Fixed air temperaute versus fixed slice temperature drying kinetics', Drying Technology, 19(9), pp. 2175-2191.

Nongalleima, K., Ajungla, T. and Singh, C. B. (2017) 'Phytochemical Screenings and AntiThrombolytic Activity of Citrus Assamenses', Journal of Medicinal Plants Studies, 5(3), pp. 114-118.

Rajkumar, P. et al. (2007) 'Drying Kinetics of Tomato Slices in Vacuum Assisted Solar and Open Sun Drying Methods', Drying Technology, 25(7-8), pp. 1349-1357.

Senadeera, W. et al. (2003) 'Influence of shapes of selected vegetable materials on drying kinetics during fluidized bed drying', Journal of Food Engineering, 58(3), pp. 277-283.

Simal, S., Femenia, A., Garau, M. C. \& Rossello, C. (2005) 'Use of exponential, Page and diffusion models to simulate the drying kinetics of kiwi fruit', Journal of Food Engineering, 66(3), pp. 323-328.

Zogzas, N. P., Maroulis, Z. B. and Marinos-Kouris, D. (1994) 'Moisture Diffusivity Methods of Experimental Determination A Review', Drying Technology, 12(3), pp. 483-515. 